\title{
Prognostic significance of dysadherin expression in advanced colorectal carcinoma
}

\author{
S Aoki ${ }^{1,4}$, T Shimamura', T Shibata', Y Nakanishi', Y Moriya ${ }^{2}$, Y Sato ${ }^{3}$, M Kitajima $^{4}$, M Sakamoto $^{1,5}$ \\ and S Hirohashi*, I \\ 'Pathology Division, National Cancer Center Research Institute, Tokyo I-I Tsukiji 5-Chome, Chuo-ku, 104-0045, Japan; ²Department of Surgery, \\ National Cancer Center Hospital, Tokyo, Japan; ${ }^{3}$ Cancer Information and Epidemiology Division, National Cancer Center Research Institute, Tokyo, Japan; \\ ${ }^{4}$ Department of Surgery, Keio University School of Medicine, Tokyo, Japan; ${ }^{5}$ Department of Pathology, Keio University School of Medicine, Tokyo, Japan
}

\begin{abstract}
A novel glycoprotein, dysadherin, has an anti-cell - cell adhesion function through downregulating E-cadherin. In this study, we investigated the expressions of dysadherin and E-cadherin in 82 patients with stage II and III colorectal carcinomas to determine the correlation between the two molecules and the clinicopathologic features of each tumour. Dysadherin was not expressed in normal colorectal epithelium. Fifty-one per cent of tumours showed dysadherin immunopositivity in over $50 \%$ of cancer cells. Thirty-eight per cent of tumours showed reduced E-cadherin immunopositivity. The increased expression of dysadherin was significantly associated with lung metastasis $(P=0.003)$. The increased expression of dysadherin had a significant impact on patient survival $(P=0.0099$ and 0.0036 , log-rank test for overall and recurrence-free survival rate, respectively). Furthermore, tumour with increased expression of dysadherin and reduced expression of E-cadherin showed the worst prognosis $(P=0.0043$ and 0.0028 , log-rank test for overall and recurrence-free survival rate, respectively). These results suggest that increased dysadherin expression is a significant indicator of poor prognosis for patients with advanced colorectal carcinoma.
\end{abstract}

British Journal of Cancer (2003) 88, 726-732. doi:I0.I038/sj.bjc.6600778 www.bjcancer.com

(C) 2003 Cancer Research UK

Keywords: dysadherin; colorectal carcinoma; immunohistochemistry; prognosis

A significant number of patients with colorectal carcinoma who undergo apparently curative resection develop local recurrence or distant metastasis (Rosen et al, 1998). Adjuvant chemotherapy or radiation therapy is needed after resection for such biologically aggressive colorectal carcinomas. Therefore, identification of factors that accurately predict prognosis is essential.

Cell - cell interactions play pivotal roles in the maintenance and development of normal tissue (Takeichi, 1990). In cancerous tissues, disintegration of cell - cell interactions and dissemination of cancer cells lead to invasive and metastatic growth (Hirohashi, 1998). Cadherins are calcium-dependent cell adhesion molecules that play an essential role in normal growth and development via mediation of homophilic cell - cell association (Takeichi, 1990). Several studies have reported that decreased function of E-cadherin is associated with tumour progression in many cancers, and in particular E-cadherin acts as a suppressor of invasive ability (Behrens et al, 1989; Vleminckx et al, 1991; Hirohashi, 2000). Many immunohistochemical studies evaluating E-cadherin expression in tumour tissues have demonstrated that reduced expression of E-cadherin is frequently observed in cancer progression (Katagiri et al, 1995; Lipponen and Eskelinen, 1995; Yonemura et al, 1995; Tamura et al, 1996; Nakanishi et al, 1997; Umbas et al, 1997;

*Correspondence: Dr S Hirohashi; E-mail: shirohas@ncc.go.jp Received 27 August 2002; revised 21 November 2002; accepted 2 December 2002
Bankfalvi et al, 1999; Ghadimi et al, 1999; Gofuku et al, 1999; Zheng et al, 1999; Kase et al, 2000).

We previously reported a novel cancer-associated cell membrane glycoprotein, dysadherin, composed of 178 amino acids. Dysadherin is expressed in a wide variety of cancer cells, but only to a limited number of normal cells such as lymphocytes, endothelial cells, and basal cells of stratified squamous epithelium. Dysadherin inactivates E-cadherin function in a post-transcriptional manner and modulates tumour aggressiveness and metastasis (Ino et al, 2002). In this study we focused on the clinicopathologic significance of dysadherin and E-cadherin expression in advanced colorectal carcinoma.

\section{MATERIALS AND METHODS}

\section{Materials}

Eighty-two routinely processed, formalin-fixed, and paraffin waxembedded blocks of colorectal carcinoma was obtained from the National Cancer Center Hospital. All cases were surgically resected between January 1990 and December 1990 at the National Cancer Center Hospital, and diagnosed as primary advanced colorectal carcinoma. The patients included 44 men and 38 women ranging in age from 37 to 93 years (mean, 62.6 years). The sample selection was restricted to consecutive cases diagnosed as stages II and III. All patients had undergone curative resection. None of the patients received chemotherapy or radiation therapy preoperatively. The 
follow-up study was complete in all patients. Recurrence after surgery was diagnosed by serum CEA level, ultrasonography, computed tomography scan, and angiography.

Thirty-five cases $(42.7 \%)$ were classified as stage II, and 47 cases (57.3\%) as stage III. Histologically, 52 cases were classified as welldifferentiated adenocarcinoma, 27 cases as moderately differentiated adenocarcinoma, two cases as mucinous carcinoma, one case as poorly differentiated adenocarcinoma, and one case as signet-ring cell carcinoma. During the follow-up period, recurrence was observed in 10 stage II cases and 17 stage III, and the recurrence proved fatal in six stage II cases and 10 stage III cases. Tumour location, tumour differentiation, liver metastasis, lung metastasis, lymph node metastasis, lymphatic invasion, and vessel invasion were all classified according to the criteria of the Japanese Society for Cancer of the Colon and Rectum (1983).

\section{Immunohistochemistry}

Immunohistochemical staining was performed on routinely processed, formalin-fixed, paraffin wax-embedded blocks of colorectal carcinoma tissues using an avidin-biotin peroxidase complex method. After deparaffinisation in xylene and rehydration in ethanol, the sections were heated in citrate buffer $(10 \mathrm{~mm}, \mathrm{pH}$ 6.0 ) at $120^{\circ} \mathrm{C}$ for $10 \mathrm{~min}$ for antigen retrieval. Endogenous peroxidase was blocked with $1 \%$ hydrogen peroxide in methanol for $20 \mathrm{~min}$. Then, sections were incubated with anti-dysadherin antibody (M53, 1:500 dilution), which had been established in our laboratory and will be described elsewhere, or anti-E-cadherin antibody (1:200 dilution, Transduction Laboratories, US) at $4{ }^{\circ} \mathrm{C}$. The sections were washed with PBS and incubated with biotinylated anti-mouse IgG antibody and avidin-biotin complex (ABC kit, Vector Laboratories, UK) and visualised using diaminobenzidine tetrahydrochloride. The sections were counterstained with haematoxylin. As an internal positive control for dysadherin staining, positive staining of endothelial cells present in the primary tumour sections was used. As an internal positive control for E-cadherin staining, positive staining of normal colorectal epithelial cells adjacent to the tumours was used; staining was normally seen at cell - cell borders. As a negative control, normal mouse immunoglobulin of the same class was used instead of the first antibody.

\section{Evaluation of E-cadherin and dysadherin expression}

Two observers (SA and TS), who had no previous knowledge of the clinical parameters and outcomes for each patient, independently reviewed the immunohistochemically stained sections; all discrepancies were resolved by joint review of the slides in question.

Expression. of dysadherin was considered positive if tumour cells were stained as strongly as adjacent endothelial cells. We assessed dysadherin expression as the percentage of positively stained tumour cells relative to total tumour cells. When over $50 \%$ of tumour cells were stained for dysadherin, the tumour was evaluated as 'positive dysadherin expression' (Dys (+)). In contrast, when fewer than $50 \%$ of tumour cells were stained for dysadherin, the tumour was evaluated as 'negative dysadherin expression' (Dys $(-)$ ).

Expression of E-cadherin was considered positive if tumour cells were stained as strongly as normal epithelial cells adjacent to the tumour, whereas those that stained more weakly than normal epithelial cells were considered negative. We also assessed Ecadherin expression as the percentage of positively stained tumour cells relative to total tumour cells. When over $80 \%$ of tumour cells were positive, the tumour was evaluated as 'preserved E-cadherin expression' (E-cad $(+)$ ). Whereas the tumour was evaluated as 'reduced E-cadherin expression' (E-cad $(-)$ ) when fewer than $80 \%$ of tumour cells were positive.

\section{Statistical analysis}

The relation of clinicopathologic characteristics to the number of immunopositive tumour cells was analysed using the $\chi^{2}$ test and ANOVA test where appropriate. Deaths from causes other than colorectal carcinoma were treated as censored cases. Recurrencefree survival and overall survival were measured from the date of surgery to the date that the recurrence was confirmed and the end of follow-up or death, respectively. Overall survival curves were determined by using the Kaplan - Meier method and were analysed with the log-rank test. Multivariate survival analysis was performed with the Cox proportional hazards regression model. Differences at $P<0.05$ were regarded as statistically significant.

\section{RESULTS}

\section{Expression of dysadherin}

Dysadherin-positive staining was observed at the membranes of cancer cells, lymphocytes, and endothelial cells as previously reported (Ino et al, 2002). Membranous dysadherin staining was localised at intercellular borders of cancer cells and was heterogeneous in tumour nests. No immunoreactivity was seen in normal colorectal epithelial cells (Figure 1A, C). Preferential expression was observed in infiltrative tumour cells in some cases (Figure 1E). The mean percentage of tumour cells that stained positively for dysadherin was $52.0 \pm 32.3 \%$ (mean \pm standard deviation (s.d.); median, 45\%). Therefore, we set the cut-off value for dysadherin immunopositivity at $50 \%$, which made it simple for observers to categorise each case according to dysadherin expression. Thirty-nine per cent (32 out of 82) of cases demonstrated immunopositivity in over $50 \%$ of cancer cells.

The correlations between dysadherin expression and various clinicopathological factors were analysed. Increased dysadherin expression was significantly correlated with lung metastasis $(P=0.003)$. There was no significant correlation between the increased expression of dysadherin and other clinicopathological factors such as age, gender, tumour location, maximum diameter of the tumour, macroscopic type, TNM stage, tumour differentiation, liver metastasis, lymphatic invasion, and vessel invasion (Table 1).

\section{Expression of E-cadherin}

E-cadherin-positive staining was observed at the cell - cell borders in normal colorectal epithelial cells and in the majority of cancer cells (Figure 1B, D). Preserved membranous E-cadherin staining, with an intensity equal to that of the adjacent normal epithelium, was present in $62.2 \%$ (51 out of 82 ) of cases (Figure 1D). Ecadherin immunoreactivity was reduced in $37.8 \%$ (31 out of 82 ) of cases (Figure 1B).

The reduced expression of E-cadherin was correlated only with lymphatic invasion $(P=0.046)$. There was no significant correlation between the reduced expression of E-cadherin and age, gender, tumour location, maximum diameter of the tumour, macroscopic type, TNM stage, tumour differentiation, liver metastasis, lung metastasis, and vessel invasion (Table 1).

In this analysis, dysadherin expression (cut-off, 50\%) was not correlated with E-cadherin expression $(P=0.3744)$ (Table 2).

\section{Prognostic value of dysadherin and E-cadherin expression}

Patients with dysadherin immunopositivity in over $50 \%$ of tumour cells survived significantly shorter than those with dysadherin immunopositivity in fewer than $50 \%$ of tumour cells $(P=0.0099$. and 0.0036 , log-rank test for overall and recurrence-free survival rates, respectively; Figure $2 \mathrm{~A}, \mathrm{~B}$ ) 

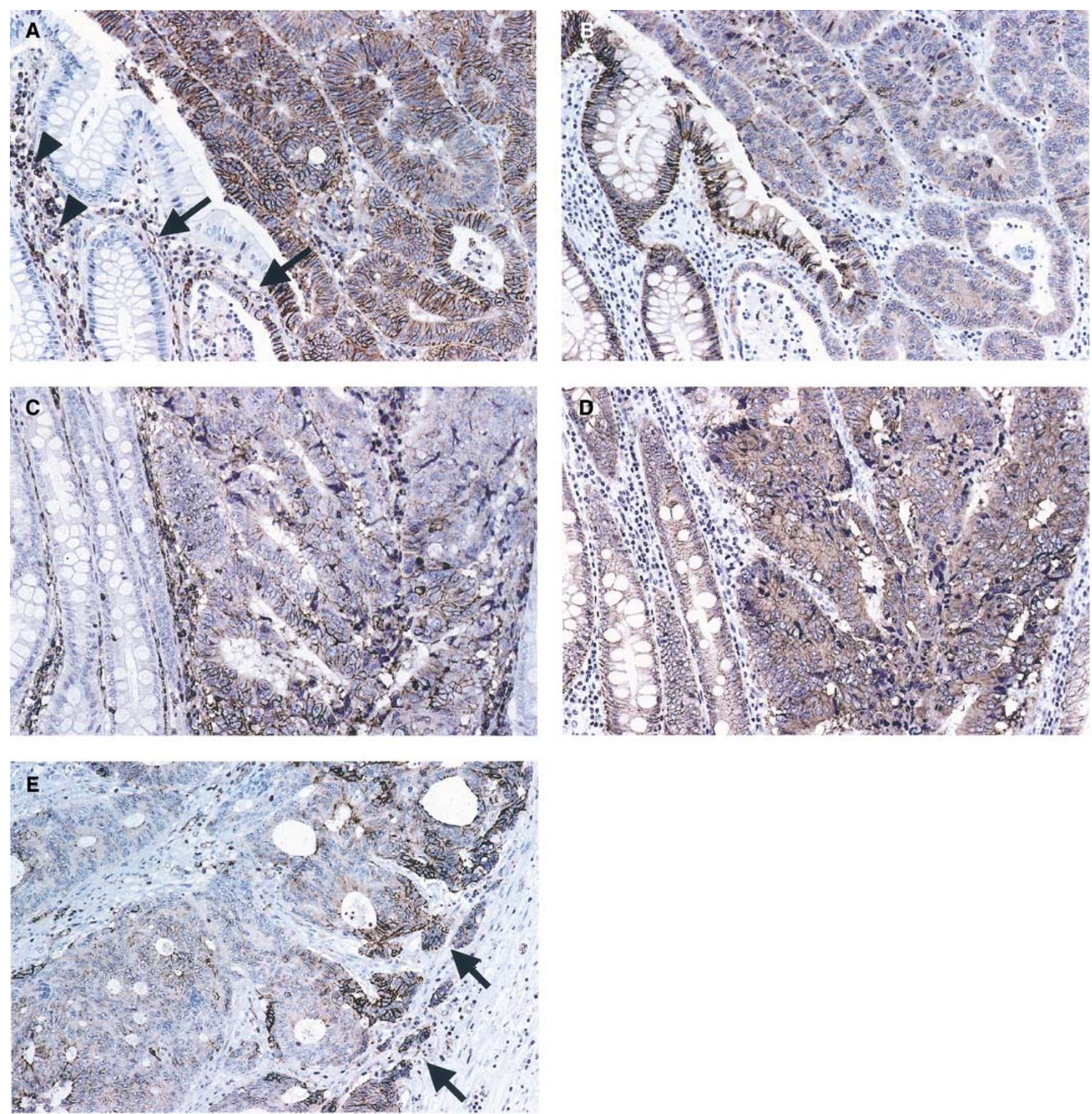

Figure I Dysadherin and E-cadherin expression in colorectal cancers demonstrated by immunohistochemistry. (A) - (D) are the adjacent sections of the same cases. (A) Dysadherin expression was observed in lymphocytes (arrowheads) and endothelial cells (arrows). Membranous dysadherin staining was localised at intercellular borders of cancer cells and was heterogeneous in tumour nests. No immunoreactivity was seen in normal colorectal epithelial cells (magnification $\times 200$ ). (B) E-cadherin expression was observed at the cell-cell borders in normal epithelial cells, and was reduced in the majority of cancer cells in this section (magnification $\times 200$ ). (C) Tumour cells were positively stained for dysadherin (magnification $\times 200$ ). (D) E-cadherin expression was not reduced in tumour cells where dysadherin was expressed (magnification $\times 200$ ). (E) Preferential dysadherin expression was observed in infiltrative tumour cells (arrow) in some cases (magnification $\times 200$ )

Patients with reduced E-cadherin immunopositivity survived significantly shorter than those with preserved E-cadherin immunopositivity $(P=0.0196$ and 0.0188 , log-rank test for overall and recurrence-free survival rates, respectively; Figure 2C, D).

Patients with combined dysadherin immunopositivity in over $50 \%$ of tumour cells and reduced E-cadherin immunopositivity survived significantly shorter than those with other combinations of dysadherin and E-cadherin immunopositivity $(P=0.0043$ and $0.0028, \log$-rank test for overall and recurrence-free survival rates, respectively; Figure 2E, F).

Multivariate analysis using Cox's proportional hazards model revealed that dysadherin immunopositivity and E-cadherin 
Table I Correlation between expression of E-cadherin and dysadherin and clinicopathological characteristics in patients with advanced colorectal carcinoma (stages II and III)

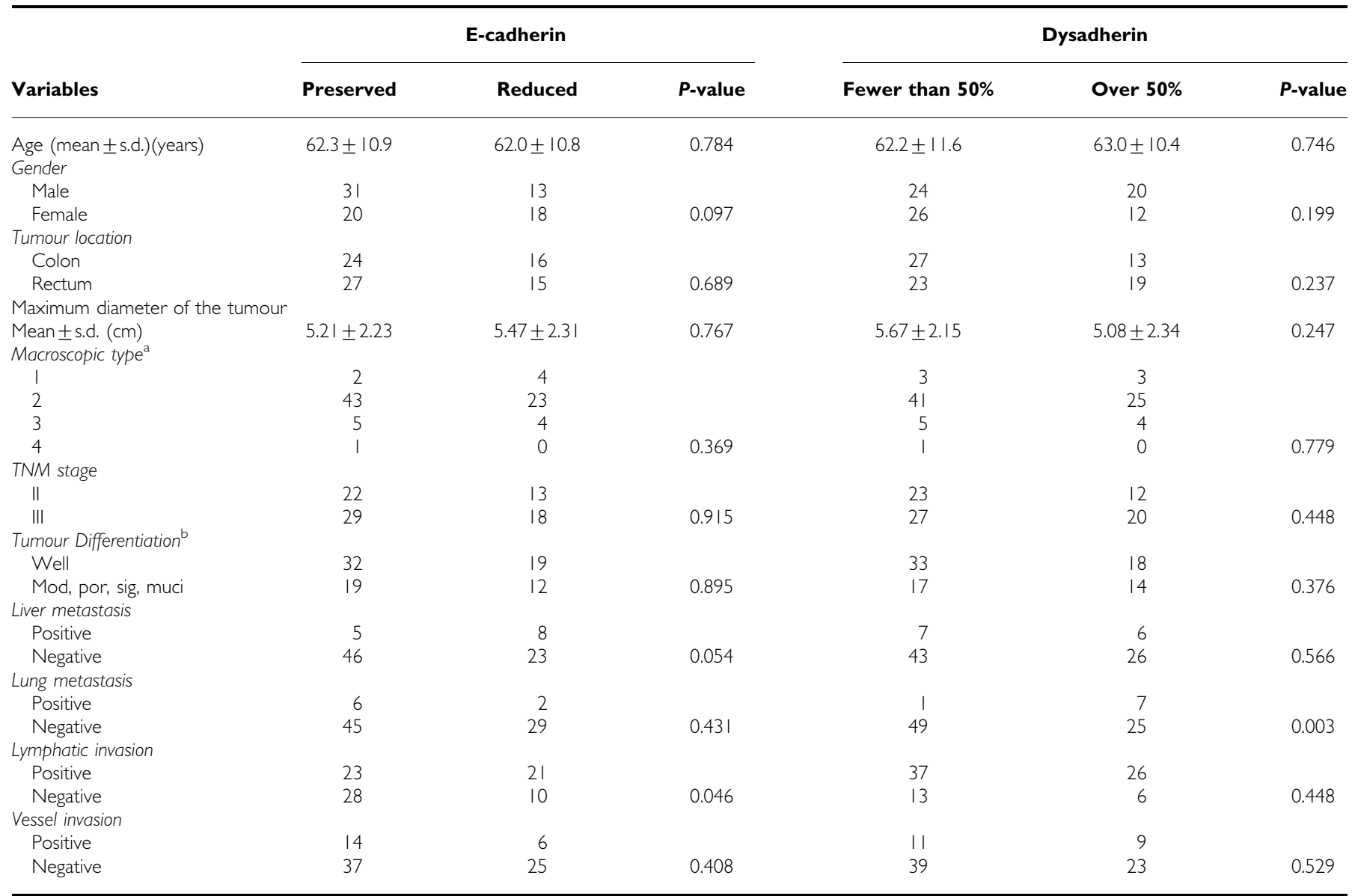

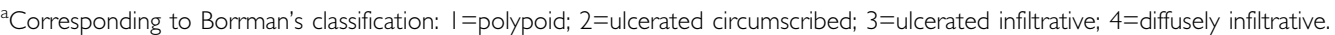

b Well=well-differentiated adenocarcinoma; mod=moderately differentiated adenocarcinoma; poor=poorly differentiated adenocarcinoma; sig=signet-ring cell carcinoma; muci=mucinous carcinoma.

Table 2 Cases classified by dysadherin expression and E-cadherin expression

\section{Dysadherin expression}

\section{E-cadherin expression}

Preserved

Reduced

$P=0.3744$.

immunopositivity were independent and significant prognostic factors when adjusted for age, gender, maximum tumour diameter, tumour differentiation, lymph node metastasis, lymphatic invasion, and vessel invasion (Table 3 ).

\section{DISCUSSION}

We reported previously that dysadherin has an anti-cell - cell adhesion function and downregulates E-cadherin, on the basis of the observation that introduction of dysadherin induced decreased the protein expression and function of E-cadherin without affecting its transcription (Ino et al, 2002). In various cancerous tissues, a reduced expression of E-cadherin has frequently been observed in cancer progression (Katagiri et al, 1995; Lipponen and Eskelinen, 1995; Yonemura et al, 1995; Tamura et al, 1996; Nakanishi et al, 1997; Umbas et al, 1997; Bankfalvi et al, 1999; Ghadimi et al, 1999; Zheng et al, 1999; Kase et al, 2000; Gofuku et al, 1999). The aim of this study was to verify immunohistochemically the hypothesis that dysadherin, which suppresses the E-cadherin system, might play a significant role in the aggressiveness of colorectal carcinoma.

As in our previous study (Ino et al, 2002), we confirmed that dysadherin was expressed heterogeneously in tumour nests, in that it was expressed in dissociating cells or infiltrative tumour nests and also in parts of well-differentiated tumour nests. As reported, dysadherin was not detected in normal colorectal epithelium, but was expressed significantly in endothelial cells. Use of these cells as internal controls allowed easy assessment of dysadherin expression by cancer cells.

The metastatic process involves a complex series of events that must include changes in the status of adhesion molecules of the tumour cells. E-cadherin, which is responsible for calciumdependent homophilic interaction between epithelial cells, has been shown to be downregulated in several tumours including colorectal carcinoma (Ghadimi et al, 1999; Gofuku et al, 1999). Several mechanisms have been proposed for the inactivation of the cadherin/catenin complex in tumour cells, such as mutations in the genes for E-cadherin, $\alpha$-catenin, and $\beta$-catenin (Hirano et al, 


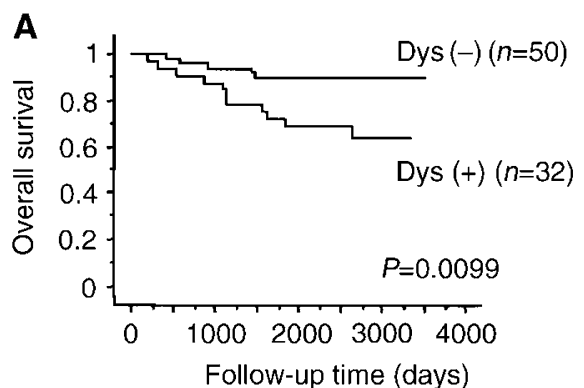

C

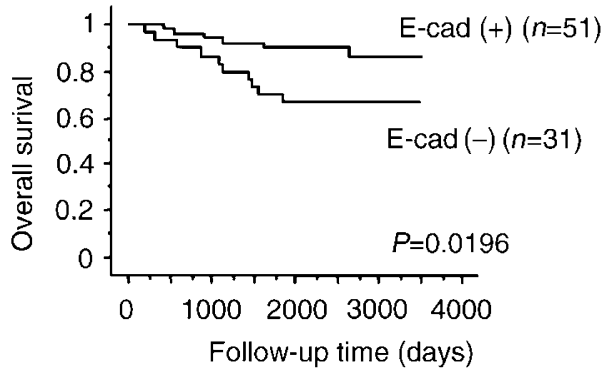

E

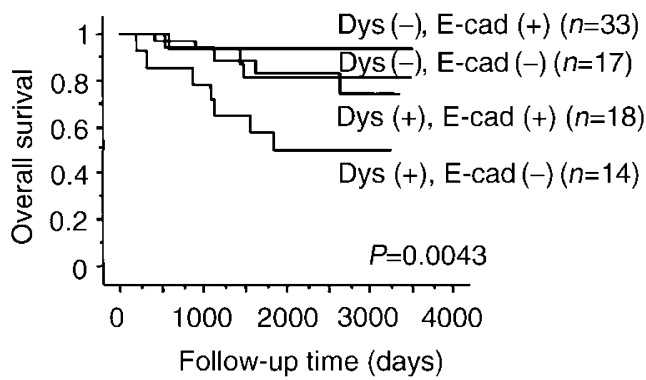

B

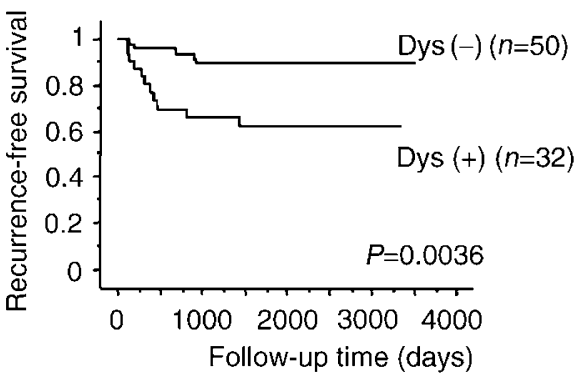

D

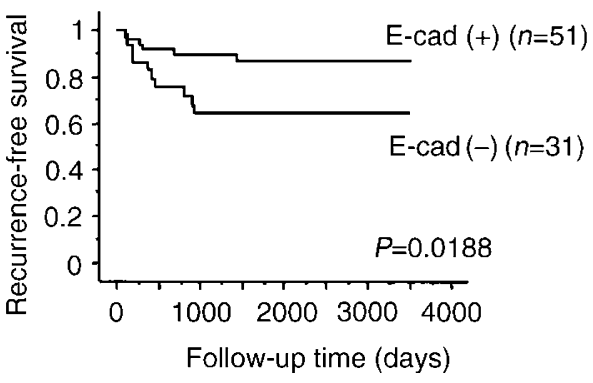

$\mathbf{F}$

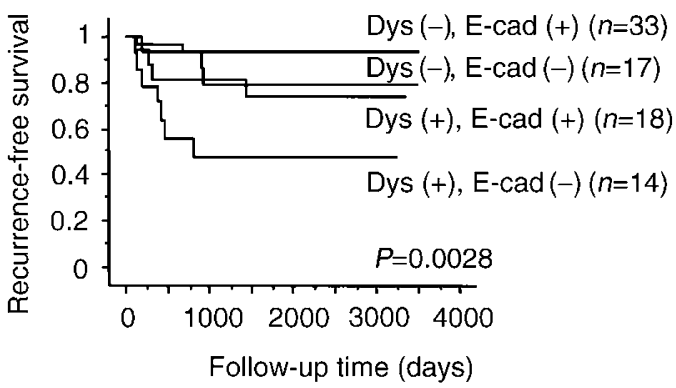

Figure 2 Overall survival $(\mathbf{A})$ and recurrence-free survival $(\mathbf{B})$ of patients in relation to dysadherin expression (log-rank test for trend: $P=0.0 \mathrm{I} 0,0.004$, respectively). Overall survival (C) and recurrence-free survival (D) of patients in relation to E-cadherin expression (log-rank test for trend: $P=0.020,0.020$, respectively). Overall survival $(\mathbf{E})$ and recurrence-free survival $(\mathbf{F})$ of patients in relation to the combination of dysadherin and E-cadherin expression (logrank test for trend: $P=0.004,0.003$, respectively). Dys $(+)$, dysadherin expression in over $50 \%$ of tumour cells; Dys $(-)$, dysadherin expression in fewer than $50 \%$ of tumour cells; E-cad $(+)$, E-cadherin expression in over $80 \%$ of tumour cells; E-cad $(-)$, E-cadherin expression in fewer than $80 \%$ of tumour cells.

Table 3 Multivariate Cox's proportional hazard analysis

\begin{tabular}{|c|c|c|c|c|c|c|}
\hline \multirow[b]{2}{*}{ Prognostic factors } & \multicolumn{3}{|c|}{ Overall survival } & \multicolumn{3}{|c|}{ Recurrence-free survival } \\
\hline & HR & $95 \% \mathrm{Cl}$ & $P$-value & HR & $95 \% \mathrm{Cl}$ & $P$-value \\
\hline Dysadherin & 3.497 & $|.032-| 1.85 \mid$ & 0.0444 & 2.522 & $1.064-5.977$ & 0.0356 \\
\hline E-cadherin & 3.588 & $1.075-11.982$ & 0.0378 & 2.393 & $1.013-5.653$ & 0.0466 \\
\hline Gender & 0.957 & $0.957-0.264$ & 0.9468 & 0.91 & $0.363-2.282$ & 0.8412 \\
\hline Age & 3.751 & $0.533-26.372$ & 0.184 & 1.339 & $0.372-4.822$ & 0.6554 \\
\hline Maximum diameter of the tumour & 1.729 & $0.379-7.886$ & 0.4793 & 1.164 & $0.408-3.324$ & 0.7765 \\
\hline Tumour differentiation (well vs others) & 2.116 & $0.612-7.323$ & 0.2366 & 1.2 & $0.479-3.009$ & 0.6972 \\
\hline Lymphatic invasion & 1.143 & $0.247-5.281$ & 0.864 & 1.406 & $0.450-4.388$ & 0.5578 \\
\hline Vessel invasion & 1.601 & $0.379-6.767$ & 0.5219 & 1.262 & $0.449-3.546$ & 0.6592 \\
\hline Lymph node metastasis & 1.213 & $0.367-4.013$ & 0.7516 & 1.538 & $0.639-3.702$ & 0.3369 \\
\hline
\end{tabular}

$\mathrm{HR}=$ hazard ratio; $\mathrm{Cl}=$ confidence interval.

1992; Oda et al, 1994; Oyama et al, 1994; Machado et al, 1999), hypermethylation around the promoter region of the E-cadherin gene (Yoshiura et al, 1995), and aberrant tyrosine phosphorylation of $\beta$-catenin (Behrens et al, 1993). In this study, reduced E-cadherin expression was observed in $37.8 \%$ (31 out of 82 ) of tumours, which was less than reported previously (Dorudi et al, 1995; Mohri, 1997; Ikeguchi et al, 2000). This discrepancy may be a result of the different evaluation system for immunopositivity or of the different cases examined; we restricted sample selection to consecutive cases diagnosed as stages II and III. However, as in previous studies (Dorudi et al, 1995; Mohri, 1997; Ikeguchi et al, 2000), the present immunohistochemical data demonstrate that reduced E-cadherin expression is significantly correlated with poor survival. 
We demonstrated previously that dysadherin had some role in post-transcriptional downregulation of E-cadherin (Ino et al, 2002). In this immunohistochemical study, although dysadherin was detected in part of some tumours, where E-cadherin expression was decreased, positive dysadherin expression was not correlated with reduced E-cadherin expression. This result suggests that mechanisms may exist for the reduction of $\mathrm{E}$ cadherin expression other than that related to dysadherin expression. Our immunohistochemical data also demonstrate that increased dysadherin expression is significantly correlated with poor survival. Furthermore, tumours with both increased expression of dysadherin and reduced expression of E-cadherin showed the worst prognosis, and tumours with the opposite combination of the two molecules showed the best prognosis. These results suggest that dysadherin expression might be an excellent indicator of the patients with advanced colorectal carcinoma and the combined immunohistochemical analysis of dysadherin and Ecadherin expression could give us further prognostic information. In the current study we categorised patients simply into two groups setting the cut-off value for dysadherin immunopositivity at $50 \%$, on the ground that the mean percentage of dysadherinpositive tumour cells was $52.0 \pm 32.3 \%$ (mean \pm s.d.; median, $45 \%$ ). We also confirmed the prognostic importance of dysadherin positivity by classifying dysadherin expression into four categories $(0-10,10-30,30-50$, more than $50 \%$ positivity) (data not shown).

Although curative resection of advanced colorectal carcinoma without synchronous distant metastasis (ie stage II or III) is feasible, a significant number of patients develop local recurrence or distant metastasis heterochronously (Newland et al, 1995; Rosen et al, 1998). Liver metastasis is an important prognostic determinant for the clinical prognosis of colorectal carcinoma (Doci et al, 1991; Wanebo et al, 1996; Rees et al, 1997). Therefore, a prognostic indicator correlated with liver metastasis and that can be assessed at the time of resection of the primary tumour is required to aid in the selection of patients for adjuvant therapy. Tumour suppressor genes such as nm23 (Yamaguchi et al, 1993), DCC (Saito et al, 1999) and Smad4 (Miyaki et al, 1999) have been reported to play a role in liver metastasis. As for adhesion molecules, reduction of the E-cadherin-catenin system (Hirohashi,

\section{REFERENCES}

Bankfalvi A, Terpe HJ, Breukelmann D, Bier B, Rempe D, Pschadka G et al (1999) Immunophenotypic and prognostic analysis of E-cadherin and beta-catenin expression during breast carcinogenesis and tumour progression: a comparative study with CD44. Histopathology 34: $25-34$

Behrens J, Mareel MM, Van Roy FM, Birchmeier W (1989) Dissecting tumour cell invasion: epithelial cells acquire invasive properties after the loss of uvomorulin-mediated cell - cell adhesion. J Cell Biol 108: 2435 - 2447

Behrens J, Vakaet L, Friis R, Winterhager E, Van Roy F, Mareel MM et al (1993) Loss of epithelial differentiation and gain of invasiveness correlates with tyrosine phosphorylation of the E-cadherin/beta-catenin complex in cells transformed with a temperature-sensitive v-SRC gene. $J$ Cell Biol 120: $757-766$

Doci R, Gennari L, Bignami P, Montalto F, Morabito A, Bozzetti F (1991) One hundred patients with hepatic metastases from colorectal cancer treated by resection: analysis of prognostic determinants. Br J Surg 78: $797-801$

Dorudi S, Hanby AM, Poulsom R, Northover J, Hart IR (1995) Level of expression of E-cadherin mRNA in colorectal cancer correlates with clinical outcome. Br J Cancer 71: 614-616

Ghadimi BM, Behrens J, Hoffmann I, Haensch W, Birchmeier W, Schlag PM (1999) Immunohistological analysis of E-cadherin, alpha-, beta- and gamma-catenin expression in colorectal cancer: implications for cell adhesion and signaling. Eur J Cancer 35: 60-65

Gofuku J, Shiozaki H, Tsujinaka T, Inoue M, Tamura S, Doki Y et al (1999) Expression of E-cadherin and alpha-catenin in patients with colorectal
1998) and expression of variant CD44 (Wielenga et al, 1993) have been studied as biological markers of liver metastasis. In the previous study (Ino et al, 2002), we demonstrated that dysadherin promoted the metastatic activity by in vivo metastasis assay. In this study positive dysadherin expression was observed in six of 13 cases, which developed liver metastasis postoperatively. Considering that various mechanisms may be involved in liver metastasis and stage IV colorectal carcinoma, including synchronous liver metastasis, were out of subject in our current study, further analysis will be required to examine the relation between dysadherin expression and liver metastasis.

Interestingly, positive dysadherin expression was observed in seven of eight cases which developed lung metastasis heterochronously. In three out of those eight cases, the metastatic lesions were surgically resected. Immunohistochemically, dysadherin was expressed heterogeneously in all three lung metastatic lesions as much as in the corresponding primary tumours (data not shown). Although the process of lung metastasis of colorectal carcinoma is still unclear, dysadherin might present a predictive information at the time of the resection of primary lesion.

In conclusion, we have demonstrated a significant correlation between the expression of dysadherin and the prognosis of patients with advanced colorectal carcinoma. Univariate and multivariate analyses revealed that the expression of dysadherin in tumour cells might be an excellent and independent prognostic indicator for patients with advanced colorectal carcinoma.

\section{ACKNOWLEDGEMENTS}

We thank Ms Y Yamauchi for her expert technical assistance. S Aoki and T Shimamura contributed equally to this work. S Aoki and T Shimamura are Awardees of a Research Resident Fellowship from the Foundation for Promotion of Cancer Research in Japan. This research was supported in part by a Grant-in-Aid for the Second Term Comprehensive 10-Year Strategy for Cancer Control from the Ministry of Health and Welfare, Japan, and by a Grant-inAid for Scientific Research (A) from the Ministry of Education, Science, Sports and Culture.

carcinoma. Correlation with cancer invasion and metastasis. Am J Clin Pathol 111: 29 - 37

Hirano S, Kimoto N, Shimoyama Y, Hirohashi S, Takeichi M (1992) Identification of a neural alpha-catenin as a key regulator of cadherin function and multicellular organization. Cell 70: 293-301

Hirohashi S (1998) Inactivation of the E-cadherin-mediated cell adhesion system in human cancers. Am J Pathol 153: 333-339

Hirohashi S (2000) Molecular aspects of adhesion-epigenetic mechanisms for inactivation of the E-cadherin-mediated cell adhesion system in cancers. Verh Dtsch Ges Pathol 84: 28-32

Ikeguchi M, Taniguchi T, Makino M, Kaibara N (2000) Reduced E-cadherin expression and enlargement of cancer nuclei strongly correlate with hematogenic metastasis in colorectal adenocarcinoma. Scand J Gastroenterol 35: $839-846$

Ino $\mathrm{Y}$, Gotoh $\mathrm{M}$, Sakamoto $\mathrm{M}$, Tsukagoshi K, Hirohashi S (2002) Dysadherin, a cancer-associated cell membrane glycoprotein, downregulates E-cadherin and promotes metastasis. Proc Natl Acad Sci USA 99: $365-370$

Japanese Research Society for Cancer of the Colon and Rectum (1983) General rules for clinical and pathological studies on cancer of the colon, rectum and anus. Part I. Clinical classification. Jpn J Surg 13: $557-573$

Kase S, Sugio K, Yamazaki K, Okamoto T, Yano T, Sugimachi K (2000) Expression of E-cadherin and beta-catenin in human non-small cell lung cancer and the clinical significance. Clin Cancer Res 6: 4789-4796

Katagiri A, Watanabe R, Tomita Y (1995) E-cadherin expression in renal cell cancer and its significance in metastasis and survival. Br J Cancer 71: $376-379$ 
Lipponen PK, Eskelinen MJ (1995) Reduced expression of E-cadherin is related to invasive disease and frequent recurrence in bladder cancer. J Cancer Res Clin Oncol 121: 303-308

Machado JC, Soares P, Carneiro F, Rocha A, Beck S, Blin N et al (1999) E-cadherin gene mutations provide a genetic basis for the phenotypic divergence of mixed gastric carcinomas. Lab Invest 79: 459-465

Miyaki M, Iijima T, Konishi M, Sakai K, Ishii A, Yasuno M et al (1999) Higher frequency of Smad4 gene mutation in human colorectal cancer with distant metastasis. Oncogene 18: 3098-3103

Mohri Y (1997) Prognostic significance of E-cadherin expression in human colorectal cancer tissue. Surg Today 27: 606-612

Nakanishi Y, Ochiai A, Akimoto S, Kato H, Watanabe H, Tachimori Y et al (1997) Expression of E-cadherin, alpha-catenin, beta-catenin and plakoglobin in esophageal carcinomas and its prognostic significance: immunohistochemical analysis of 96 lesions. Oncology 54: 158-165

Newland RC, Dent OF, Chapuis PH, Bokey L (1995) Survival after curative resection of lymph node negative colorectal carcinoma. A prospective study of 910 patients. Cancer 76: 564-571

Oda T, Kanai Y, Oyama T, Yoshiura K, Shimoyama Y, Birchmeier W et al (1994) E-cadherin gene mutations in human gastric carcinoma cell lines. Proc Natl Acad Sci USA 91: 1858-1862

Oyama T, Kanai Y, Ochiai A, Akimoto S, Oda T, Yanagihara K et al (1994) A truncated beta-catenin disrupts the interaction between E-cadherin and alpha-catenin: a cause of loss of intercellular adhesiveness in human cancer cell lines. Cancer Res 54: $6282-6287$

Rees M, Plant G, Bygrave S (1997) Late results justify resection for multiple hepatic metastases from colorectal cancer. Br J Surg 84: 1136-1140

Rosen M, Chan L, Beart Jr RW, Vukasin P, Anthone G (1998) Follow-up of colorectal cancer: a meta-analysis. Dis Colon Rectum 41: 1116-1126

Saito M, Yamaguchi A, Goi T, Tsuchiyama T, Nakagawara G, Urano T et al (1999) Expression of DCC protein in colorectal tumours and its relationship to tumour progression and metastasis. Oncology 56: 134-141
Takeichi M (1990) Cadherins: a molecular family important in selective cell - cell adhesion. Annu Rev Biochem 59: 237-252

Tamura S, Shiozaki H, Miyata M, Kadowaki T, Inoue M, Matsui S et al (1996) Decreased E-cadherin expression is associated with haematogenous recurrence and poor prognosis in patients with squamous cell carcinoma of the oesophagus. Br J Surg 83: 1608-1614

Umbas R, Isaacs WB, Bringuier PP, Xue Y, Debruyne FM, Schalken JA (1997) Relation between aberrant alpha-catenin expression and loss of E-cadherin function in prostate cancer. Int J Cancer 74: 374-377

Vleminckx K, Vakaet Jr L, Mareel M, Fiers W, van Roy F (1991) Genetic manipulation of E-cadherin expression by epithelial tumour cells reveals an invasion suppressor role. Cell 66: 107-119

Wanebo HJ, Chu QD, Avradopoulos KA, Vezeridis MP (1996) Current perspectives on repeat hepatic resection for colorectal carcinoma: a review. Surgery 119: $361-371$

Wielenga VJ, Heider KH, Offerhaus GJ, Adolf GR, van den Berg FM, Ponta $\mathrm{H}$ et al (1993) Expression of CD44 variant proteins in human colorectal cancer is related to tumour progression. Cancer Res 53: $4754-4756$

Yamaguchi A, Urano T, Fushida S, Furukawa K, Nishimura G, Yonemura Y et al (1993) Inverse association of $\mathrm{nm} 23-\mathrm{H} 1$ expression by colorectal cancer with liver metastasis. Br J Cancer 68: 1020-1024

Yonemura Y, Nojima N, Kaji M, Fujimura T, Itoh H, Ninomiya I et al (1995) E-cadherin and urokinase-type plasminogen activator tissue status in gastric carcinoma. Cancer 76: $941-953$

Yoshiura K, Kanai Y, Ochiai A, Shimoyama Y, Sugimura T, Hirohashi S (1995) Silencing of the E-cadherin invasion-suppressor gene by CpG methylation in human carcinomas. Proc Natl Acad Sci USA 92: 7416 - 7419

Zheng Z, Pan J, Chu B, Wong YC, Cheung AL, Tsao SW (1999) Downregulation and abnormal expression of E-cadherin and beta-catenin in nasopharyngeal carcinoma: close association with advanced disease stage and lymph node metastasis. Hum Pathol 30: 458-466 